\title{
DESCRIBING THE VERTICAL STRUCTURE OF INFORMAL SETTLEMENTS ON THE BASIS OF LIDAR DATA - A CASE STUDY FOR FAVELAS (SLUMS) IN SAO PAULO CITY
}

\author{
S. C. L. Ribeiro ${ }^{1,3 *}$, M. Jarzabek-Rychard ${ }^{2}$, J. P. Cintra ${ }^{3}$, H.-G. Maas ${ }^{4}$ \\ ${ }^{1}$ Urbanism Secretariat, Sao Paulo City Hall, Sao Paulo, Brazil, sribeiro@ prefeitura.sp.gov.br \\ ${ }^{2}$ Institute of Geodesy and Geoinformation Science, Technische Universität Berlin, 10623 Berlin Germany, \\ malgorzata.jarzabek-rychard@tu-berlin.de \\ ${ }^{3}$ Polytechnic School and Paulista Museum, Sao Paulo University, Brazil - jpcintra@usp.br \\ ${ }^{4}$ Institute of Photogrammetry and Remote Sensing, Technische Universität Dresden, 01069 Dresden Germany, \\ hans-gerd.maas@tu-dresden.de
}

KEY WORDS: Airborne Laser Scanning (ALS), Segmentation, Agglomerated Building, Built Area, Building Height, TypoMorphology

\begin{abstract}
:
Cadastral mapping of favela's agglomerated buildings in informal settlements at Level of Detail 1 (LoD1) usually requires specific surveys and extensive manual data processing. Therefore, there is a demand for including the favelas in the city map production on the basis of Lidar surveys, as well as the detection of their vertical growth. However, the currently developed algorithms for automatically extracting buildings from airborne Lidar data have mainly been tested only for regular building reconstruction. This study aims to develop a Lidar data processing pipeline enabling to compute metrics related to intraurban informal settlements. To do so, we present a procedure to generate favela's buildings delineation, height, floors' number and built area and apply them to six case studies in favela typo-morphologies. We conducted an exploratory analysis in order to obtain the adequate parameters of the processing pipeline and its evaluation, using open source, free license and self-developed software. The results are compared to reference data from the manual stereo plotting, achieving a quality index in the building reconstruction about $70 \%$. We also calculated the growth density, measured by gross Floor Area Ratio index inside settlement, revealing values from $29 \%$ to $74 \%$ considering different time periods.
\end{abstract}

\section{INTRODUCTION}

\subsection{Informal settlements in Sao Paulo mega city}

According to 2012 information of United Nations ${ }^{1}, 863$ million people lived in informal settlements all over the world. There is a projection that in 2030 about 3 billion people (or $40 \%$ of the world population) will demand proper housing and assessment to basic infrastructure and services ${ }^{2}$. In order to ameliorate human living in terms of inclusion, safety, resilience and sustainability (Goal $11-2030$ Agenda $^{3}$ ), it is imperative to have detailed information about settlements. Information quality is a key factor to allow the participation of citizens through "incremental improvements" (Martine \& McGranahan, 2010). Informal settings are especially worrisome in development countries, and cities in Latin America can be highlighted in this way. For instance, Sao Paulo, the most populous city of the Southern Hemisphere, has 11,253,503 inhabitants and a population density of 7,398 people/ $/ \mathrm{km}^{2}$ (IBGE, 2010). Despite being the Brazil's richest city, it has around 6,442 informal settlements ${ }^{4}$. These settlements are implemented in discordance with land and building regulations and usually lack public services and infrastructure. The three typo-morphologies Brazilians' informal settlements are: Tenements/cortiços, irregular/clandestine parcelling and Favelas. Tenement or Cortiço is high density collective housing in city's centre. They are old and subdivided into small rooms with many fire and explosive hazards, few bathrooms, no formal rental relationships, no proof of payments, and often run by intermediaries connected to the police and criminals (Saule Jr.,

\footnotetext{
* Corresponding author

${ }^{1} \mathrm{https} / / / \mathrm{www} . u n . o r g /$ ruleoflaw/un-and-the-rule-of-law/united-nationshuman-settlements-programme/ in 21/06/2018 ${ }^{2} \mathrm{http} / /$ unhabitat.org/urban-themes/housing-slum-upgrading/ in $24 / 05 / 18$.

${ }^{3}$ https://sustainabledevelopment.un.org/sdg11 in 21/06/18 ${ }^{4}$ http://www.habitasampa.inf.br/habitacao/ in 24/05/18
}

1999). Irregular parcelling is usually irregularly and/or illegally developed in peripheral areas, presents precarious technical conditions, and are not registered in the public registry office. The parcelling developed in areas of contested ownership are called "clandestine". The occupiers have bought their plots from whoever presented themselves as landowners, and in most of cases paid all due taxes (Lall et al., 2007).

Favela is the most popular one. They are precarious human settlements resulting from the invasion of both public and private urban areas. Those invaded areas are generally located near city centres, but mostly unsuitable for human occupation due to geographical and ecological factors. They lack in many aspects of urban infrastructure and collective equipment. The favela typo-morphology can be exemplified in Figure 1, usually characterized by aggregated buildings, different and irregular building heights, small building sizes, simplicity in the shape of roofs, narrow streets/pathways, etc.

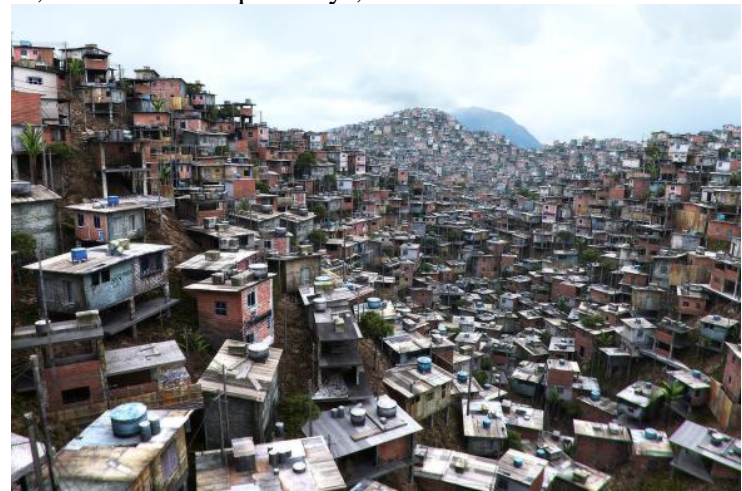

Figure 1. Favela typo-morphology.

Source: Andrew Gavin Marshall. Available at https://andrewgavinmarshall.com/tag/slums/

According to 2010 census, Sao Paulo municipality has 2,134 favelas (including the upgraded ones) occupying 4,404.63 ha, encompassing $11.38 \%$ of the total population of the city, which results in very high built densities (Pasternak \& D'Ottaviano, 
2016). In addition, the other typo-morphologies of informal settlements, i.e. parcelling and tenements/cortiços, add 4,308 perimeters, totalizing 6,442 heterogeneous settlements.

\subsection{Informal settlements mapping}

Most of the detection and monitoring works on informal settlements at the global level use orbital sensors and are mainly motivated by the Sustainable Development Goals (Kuffer et al., 2016). The evident evolution of very-high-resolution (VHR) imagery triggered the development of automated processing methods. However, additional data (population, geomorphology, infrastructure and urbanism) do not have a systematic acquisition in these areas. In addition, as already mentioned, in São Paulo there is not a single typomorphological pattern for informal, and obviously around the world this diversity presents great challenges for their mapping. Ioannidis et al. (2009) aiming to monitor the informal constructions in suburban areas outside the urban plans, compared two digital surface models (DSM) of the same area in two different time periods. Digital orthoimages of $0.25 \mathrm{~m}$ ground resolution (GSD) accompanied by digital terrain models (DTM) of $1 \mathrm{~m}$ grid size were their data source.

Taubenbock \& Kraff (2014) used a manual derivation of individual buildings by visual digitization based on VHR optical satellite data aiming to produce comparable metrics.

In two informal settlements, "the flexible data acquisition and high spatial resolution" acquired by RGB cameras on unmanned aerial vehicles (UAVs) gave motivation to Gevaert et al. (2017) combine data from ortho-imagens, DSM and point cloud, both post-processing generated by Pix4D software. This data set was used to analyse the feature extraction and integration, including the building heights, calculated by DSM top-hat filter algorithm. The image acquisition quickness and less occlusion factors are some positive side of use UAVs; however, the three lacks, do not have consolidated legislation, systematic survey and control by municipalities, can be arguments to nonprioritizing this resource to the informal areas.

Taubenbock et al. (2018) adopted Google Street View (GSV) for visual floor counting in informal settlements on selected locations around the world. The first limitation to use this procedure is that it is not possible to see the under or upper ground floors occluded from the street view; the second limitation is that GSV covering on favelas is rare or unsystematic.

Mahabir et al. (2018) argued that to develop a more comprehensive framework, to detect and map slums, other emerging sourcing of geospatial data should be considered (e.g., volunteer geographic information) in conjunction with growing trends and advancements in technology (e.g., geosensor networks). It is worth highlighting from this review, the pros and cons of the census survey data and the building feature extraction as techniques to three steps processing: detection, delineation and characterization.

\subsection{Buildings from Lidar data}

Airborne Laser Scanning (ALS) is an option for systematic and controlled survey and, currently, only airborne has legislation and quality control well established by service companies and local government contractors. Some of the biggest Brazilian cities have already conducted the Lidar survey (Belo Horizonte with 2,375,151 inhabitants, Rio de Janeiro with 6,320,446 inhabitants, Salvador with 2,675,656 inhabitants and Campinas with 1,080,113 inhabitants, e.g.), but these cities still have not properly explored their potential for cadastral and intervention applications. In fact, Sao Paulo has been conducting its first
Lidar-based with a city-wide coverage in an average point density of 10 points $/ \mathrm{m}^{2}$, focused on building and vegetation mapping. Here we apply simple tools to process Lidar data and to evaluate the horizontal and vertical precision at the building level, i.e., detection of the position and number of floors.

Even with the currently available technology, mapping buildings in mega cities must be improved by automation. The scientific community has developed diverse algorithms, and there are available tools for non-specialist users.

"The methods for modelling building rooftops from ALS data can be categorized into data-driven, model-driven, and hybriddriven. Data-driven use a bottom-up approach that begins with the extraction of primitives (e.g. planes) followed by analysing primitive topology in 2-D or 3-D space. Model-driven approaches involve a top-down strategy that usually begins with a hypothetical model library (composed of basic building shapes, e.g., flat gable, hip, shed, saltbox, mansard, pyramidal, and gambrel) and then uses rooftop point clouds to search for optimal solutions of model composition from the library. Hybrid modelling often uses the ground plans or sets of nonoverlapped and connected quadrilaterals to divide the complex rooftop into subsets where the solution already exists." (Wang et al., 2018)

Case-studies using the ISPRS benchmark (Rottensteiner et al., 2014) have disseminated data only for regular buildings with well-known typo-morphology; however, there is a lack of studies with agglomerated buildings. Obtaining the agglomerated buildings complexity in aerial data (photo and Lidar) is intricate, mainly because of no splitting into single buildings and because the ground is almost invisible by aerial view; consequently, no regular models can be used to individualize those buildings. Although each informal building roof type are geometrically simple, their built aggregation morphology and their small size make the processing quite difficult.

The 2.5D solution can be adopted in all GIS software as a simplest solution to $\mathrm{Z}$ value representation after the $3 \mathrm{D}$ reconstruction processing. "The purpose of reconstruction is to represent a building with as few point vertices as possible, i.e., to determine the topological primitives and their connectivity for the building. The topologic primitives of a building consist of vertices, breaklines, and segments, which are all in 3D." (Sampath \& Shan, 2008).

Wang (2013) reviewed that building modelling by ALS "has been under investigation research since the late 1980s" and "recent methods introduced an automatic pipeline of creating 3D building models from aerial Lidar data with a focus on rooftop modelling". Lu et al. (2014) performed building type classification using attributes derived from Lidar data, and compared four machine learning methods for building type classification. Awrangjeb (2015) presented an automatic building change detection technique by which buildings are automatically extracted from newly-available Lidar point cloud data and compared to those within an existing building database. Cao et al. (2017) proposed a spatial database-based framework (managing and retrieving large volumes of spatial data via parallel computation) for the reconstruction of $3 \mathrm{D}$ building roof models from airborne Lidar point datasets; their proposal contains five major components: (a) a density-based clustering, (b) an improved boundary tracing, (c) a planar extraction, (d) boundary regularization and (e) reconstruction of the topological and geometrical information of building roofs using the intersections of planar patches.

\subsection{Extracting informal buildings from Lidar}


Among different existing technologies to improve urban mapping, Lidar deserves to be explored, especially for the favelas still unmapped. The calculated built area using heights compared with a reference survey enables to monitor the growing, specially the built density growing directly affected by verticalization. Lidar can combine high resolution and vertical accuracy at sufficient level of detail requested in this typomorphology settlement.

The main challenge is to produce segments corresponding to individual but agglomerated buildings; from roof types (shed, gable, butterfly, hip, etc.), the most frequent in favelas is the flat ones. Flat planes are relatively simple for detection algorithm, however their water tanks over roof generally can difficult the processing. With this aim, the recommended survey density was around 10 points $/ \mathrm{m}^{2}$ (see Balsa-Barreiro et al., 2012; Rupnik et al., 2015, about technical specification for point density and especially Alexander et al., 2009, for point density influence on building type detection).

Although not aimed specifically for favelas, important contributions were made to solve typical problems of typomorphology present in the informal settlements. Oude Elberink (2010) tried the complexity of using the Lidar point cloud for classification, segmentation and reconstruction in a case-study similar to the informal settlement typology. Due to the built density of these areas, usually there is no free space between the buildings, which makes difficult the correct classification and building delineation. Jarzabek-Rychard \& Borkowski (2016) highlighted the need for the recognition of small roof structures, due to undetected small planes, considered a challenging task for most of the current reconstruction algorithms. The use of Lidar to detect the different heights in building closely aggregated was addressed by Jarzabek-Rychard \& Maas (2017), pointing out that "in the case of height differences within a multi-flat roof some parts of roof planes may be occluded by others (...); being challenging to precisely define a step edge only from a 3D point cloud".

To deal specifically with the point cloud processing in informal settlements, Temba et al. (2015) presented an automatic extraction from the eaves of the buildings with a routine in Matlab platform for a favela from the Brazilian city of Belo Horizonte; however, although it was an important contribution for the outline extraction step, their academic work was not implemented from the raw data to the cartographic product.

\section{DATA AND METHOD}

We consider as premises to this work: settlements are delimited and in Brazilian specific case by Census Districts considered as precarious according physical and socio-economic criteria; only Lidar data is used to generate the building polygons 2.5D; Level of Detail 1 - LoD1 (Kolbe, 2009) was considered the goal for this product; the DTM is available at proper scale generated at the same Lidar survey or by previous work; 3D scenes for visualizing is not relevant application.

\subsection{Data set}

To perform the present case study, we firstly chose six sample areas surveyed by Lidar ${ }^{5}$. Secondly, we picked out those samples by intersection according to the following criteria: Within the bounds of municipal "Special Social Interest Zones ZEIS" (Ribeiro et al., 2016) and federal "Subnormal Census Districts" (IBGE, 2010), and so the availability of reference data by municipal "Cadastral and Topographic Survey". The

\footnotetext{
${ }^{5}$ All this data will be available at Geosampa Web GIS

(http://geosampa.prefeitura.sp.gov.br) from Sao Paulo City Hall.
}

sensor used in the survey was the Optech Gemini, frequency 100-125 KHz., scan angle 18-25 deg., adopted beam divergence $0.25 \mathrm{mrad}$, average flight level $700 \mathrm{~m}$, average density 10 points $/ \mathrm{m}^{2}$. Table 1 presents the main characteristics of the building point cloud for the six sample areas. The point distribution is not homogeneous because of the redundancy resulting from overlapping flight strips. As consequence, the following criteria to minimum number of points and area to segmentation analysis will be on discussion.

\begin{tabular}{|l|l|l|c|c|c|}
\hline $\begin{array}{c}\text { Name } \\
*\end{array}$ & $\begin{array}{l}\text { Area } \\
\left(\mathrm{m}^{2}\right)\end{array}$ & $\begin{array}{l}\text { N. of } \\
\text { building } \\
\text { pts. }\end{array}$ & $\begin{array}{l}\text { N. of } \\
\text { building } \\
\text { segments }\end{array}$ & $\begin{array}{l}\text { Building } \\
\text { pt. dens. } \\
\left(\mathrm{pts} . / \mathrm{m}^{2}\right)\end{array}$ & $\begin{array}{l}\text { Spa- } \\
\text { cing } \\
(\mathrm{m})\end{array}$ \\
\hline GUA & 44,915 & 619,609 & 637 & 17.98 & 0.24 \\
\hline PIO & 41,184 & 594,470 & 521 & 16.87 & 0.24 \\
\hline MOR & 38,611 & 218,468 & 291 & 9.24 & 0.33 \\
\hline CAN & 34,187 & 120,101 & 208 & 7.37 & 0.37 \\
\hline OLA & 33,471 & 185,518 & 233 & 8.87 & 0.34 \\
\hline LUA & 42,507 & 258,782 & 383 & 9.75 & 0.32 \\
\hline
\end{tabular}

Table 1. Geometric characteristics of the samples

* The original favela names and respectively free translation are: GUA is "Guapira" ("Headwaters/Top of the Valley"), PIO is "Morro do Piolho" ("Cooties Hill"), MOR is "Vila Morumbi" ("Green Hill village"), CAN is "Canto do Rio Verde" ("Corner of the Green River"), OLA is "Olaria" ("Bricks manufacturing") and LUA is "Morro da Lua" ("Moon Hill").

The building reference data was produced by manual stereo plotting of individual polygons at 1:500 scale from flight scale $1: 3,000$. This is not a systematic way to cartographic production and that is the reason to diverse dates of these surveys of our study. The quantity $(\mathrm{N})$ of buildings for each area is presented in Table 2 separately, using the threshold $20 \mathrm{~m}^{2}$ and aiming to compare the segmentation processing adopted parameter. The total area covered by buildings (built area 2D) was calculated for all the polygons. The maximum floor number attribute $(\mathrm{N}$. floor max.) was registered in the $8^{\text {th }}$ column in order to compare with the results. The buildings of the reference data set that were in construction/foundations at the survey date are presented here as zero value (floor $=0$ ).

\subsection{Pipeline procedure}

This study aims to improve Lidar pipeline procedure bringing the possibility to compute metrics related to intraurban informal settlements.

We established the following procedure as a pipeline for the sample areas: (a) Classification of buildings and vegetation in LAS compressed format; (b) Generation of the Normalized Digital Surface Model (nDSM) for the building heights above a pre-existing Digital Terrain Model (DTM) in DXF format in lastools ${ }^{6}$; (c) Segmentation for building points, the only step by own development in $\mathrm{C}++$; (d) Boundary delineation of the segments; (e) Attributes summarization (building height and built area calculation); (f) Comparison to reference data in qgis? Google 3D and Street View were used as auxiliary source to calibrate the floor height. The last step is the metrics generation for the settlement based on Floor Area Ratio (FAR). The workflow depicted in Figure 2 represents the processed pipeline.

\footnotetext{
${ }^{6}$ LasTools is partially free and available "for education and evaluation purposes" (Isenburg, 2018). Available at: http://www.cs.unc.edu/ isenburg/lastools/license.txt Accessed in $22 / 06 / 2018$

${ }^{7}$ Qgis is a free and open source software. Available at: https://qgis.org/en/site/index.html. Accessed in 22/06/2018.
} 


\begin{tabular}{|l|c|c|c|c|c|c|c|c|}
\hline Name & $\begin{array}{c}\text { Flight date } \\
\text { (month/year) }\end{array}$ & $\begin{array}{c}\text { N polygs. } \\
\text { area } \\
\geq 20 \mathrm{~m}^{2}\end{array}$ & $\begin{array}{c}\text { N polygs. } \\
\text { area } \\
<20 \mathrm{~m}^{2}\end{array}$ & $\begin{array}{c}\text { Min area } \\
\left(\mathrm{m}^{2}\right)\end{array}$ & $\begin{array}{c}\text { Max area } \\
\left(\mathrm{m}^{2}\right)\end{array}$ & $\begin{array}{c}\text { Built area } \\
2 \mathrm{D}\left(\mathrm{m}^{2}\right)\end{array}$ & $\begin{array}{c}\mathrm{N} \\
\text { floor } \\
\max \end{array}$ & $\begin{array}{c}\text { N. polygs. in } \\
\text { construction } \\
(\text { floor}=0)\end{array}$ \\
\hline GUA & Nov/2011 & $445(80 \%)$ & $110(20 \%)$ & 2.44 & 169.44 & 25315.92 & 4 & 12 \\
\hline PIO & Mar/2016 & $342(83 \%)$ & $69(17 \%)$ & 2.56 & 206.47 & 17574.71 & 4 & 2 \\
\hline MOR & Nov/2011 & $339(83 \%)$ & $70(17 \%)$ & 6.41 & 251.97 & 20588.44 & 4 & 3 \\
\hline CAN & Nov/2011 & $233(59 \%)$ & $160(41 \%)$ & 3.06 & 415.20 & 11696.27 & 2 & 8 \\
\hline OLA & Nov/2011 & $330(87 \%)$ & $50(13 \%)$ & 3.12 & 210.17 & 16410.41 & 4 & 5 \\
\hline LUA & Mar/2014 & $457(72 \%)$ & $177(28 \%)$ & 1.58 & 411.44 & 20886.99 & 5 & 15 \\
\hline
\end{tabular}

Table 2. Characteristics of the reference data for favela's buildings

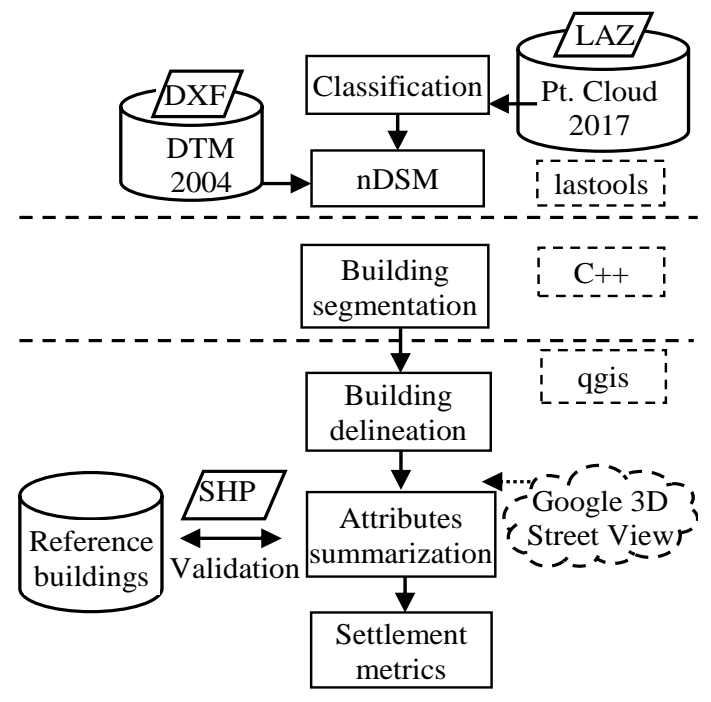

Figure 2. Method workflow

\subsubsection{Classification}

An exploratory analysis was conducted in the six sample areas to obtain thresholds about main categories to classify, coded according to $\operatorname{ASPRS}^{8}$ (2013): ground (cat. 2), height under $2.0 \mathrm{~m}$ as low vegetation (cat. 3 ), height over $2.0 \mathrm{~m}$ as high vegetation (cat. 5), building (cat. 6), to height $+/-0.2 \mathrm{~m}$ range to the mean ground and context error class, as low noise (cat. 7), wire conductors (cat. 14), height over the higher buildings or under $0.2 \mathrm{~m}$ limit the mean ground, as high noise (cat. 18). The building category was processed individually later in the next step, to reconstruct and summarize its heights and built area. The main parameters investigated were planarity and roughness to respectively detect accurately roofs and vegetation.

A terrain comparison was performed between old survey (2004) produced by manual stereo plotting at 1:1,000 scale and Lidar survey (2017), to support the choice of one of the sources for the ground category. The streets remained at the same level as well as the football/soccer field, which is the only frequently preserved free area, but other parts inside the agglomerated were quite modified by cut and fill. A comparison was made from both DTMs to give confidence to 2004 source adopted under the buildings, due to the intrinsic subjectivity of the DTM generated underneath the vegetation and buildings, either for stereo plotting or for Lidar survey.

\subsubsection{Normalization}

\footnotetext{
8 https://www.asprs.org/a/society/committees/standards/LAS_1_4_r13.pdf
}

To identify how much area and how many floors were built, the study produced the height difference about building points and the ground surface (Triangulated Irregular Network - TIN) generated from pre-existing DTM with the proper quality control performed and proven, to assign the new height above ground level (AGL) attribute to each building point. Older topographic maps are available in digital format and are the best reference for terrain because an important characteristic of informal occupation is their quick appearance, so the acquisition of the recent/new settlements that were built over the old ground gives more accurate values for building height. The built density for these settlements is the main reason to occlusion of the terrain surface.

\subsubsection{Segmentation}

A standard region growing approach was implemented in $\mathrm{C}++^{9}$. CGAL library was used for standard computation algorithms, while OpenGL served for visualization purposes. Details about the algorithm are available in Jarzabek-Rychard \& Borkowski (2016).

The n-nearest neighbours of each point were used to estimate a best local fitting plane. In addition to normal vector computation technique, points with corresponding local planes of small residuals were then selected as seed regions. Within the following region growing step, points adjacent to this seed region were iteratively added to the plane if they were compatible to the actual plane. In order to fulfil this compatibility criterion, the vertical distance to the plane and the normal vector difference must be below a certain threshold. The criteria for segmentation using the height above sea level of the building points according were: local consistency of a segment defined by the maximum distance of the neighbourhood; locally smooth surface defined by the angle between the normal vectors of the candidate point and the growing plane; globally flat surface defined by the distance between the candidate point and the growing plane. The parameter thresholds were set interactively depending on the quality and characteristics of the data. Table 3 shows the explicitly defined parameters adopted for segmentation for the sampled favelas.

\begin{tabular}{|c|c|}
\hline Parameter & Value \\
\hline $\begin{array}{l}\text { Maximum horizontal distance of the } \\
\text { neighbourhood }(\mathrm{m})\end{array}$ & 0.8 \\
\hline $\begin{array}{l}\text { Angle between the normal vectors of the } \\
\text { candidate point and the growing plane (deg) }\end{array}$ & 45 \\
\hline $\begin{array}{l}\text { Vertical distance between the candidate point } \\
\text { and the growing plane }(\mathrm{m})\end{array}$ & 0.4 \\
\hline Minimum segment size (number of points) & 200 \\
\hline
\end{tabular}

Table 3. Parameters for segmentation

\footnotetext{
${ }^{9}$ The code is available in the Institute of Geodesy and Geoinformation Science, Technische Universität Berlin and for cooperation institute.
} 


\subsubsection{Delineation}

The delineation of the segments was defined by a K-nearest neighbours' algorithm (Moreira \& Santos, 2007), and they were used directly, i.e., without additional geometric simplification. The main parameter was the number of neighbours, initially set to 200 for all segments and, after topological corrections adapted to 20 for more complex boundaries. Each polygon was computed as a unique building. The number of buildings is presented in the $2^{\text {nd }}$ and $3^{\text {rd }}$ columns of Table 5. The final shape of the building polygons was generated using a Douglas \& Peucker like algorithm, "to determine the outlining polygon such that all points are on the inside of the polygon" (Maas \& Vosselmann, 1999). As the authors mentioned, the non-parallel and perpendicular lines of buildings are "visually unattractive", however for the median height computation is more relevant to consider all the points detected.

\subsubsection{Attributes summarization}

Despite of the complexity of the building, the height was determined by median values of the roof points from all the points of each segment. The reason for choosing the median was the non-uniform distribution and redundancy of the point cloud generated by overlapping flight strips, even though the small size of buildings minimizes this factor here.

The height for each building was calculated above the ground (pre-existing survey for DTM) to define the number of floors considering the storey height calibration based on Google Street View. The building height is the main result, and it is translated into the number of floors. The threshold height values were assigned to each polygon (building) in a way to produce the number of floors value as an attribute.

Aiming to calibrate the floor height, samples were made on buildings that didn't change since reference survey. Four criteria were considered to sort the sample: (a) Minimum relief variation on the street to avoid slope variation; (b) Google street view and $3 \mathrm{D}$ and respective up to date, although the favelas have partial and heterogeneous covering; (c) Aerial photo 2017 to verify some changing; (d) Number of floors values from reference survey (reference data) and its height result was the same.

For the samples, we adopted $3.0 \mathrm{~m}$ for $1^{\text {st }}$ and $2.5 \mathrm{~m}$ for other floors as thresholds, implemented as a simple CASE function:
CASE when "medianHeight" < "threshold" then "nFloor"

The zero value for the number of floor was assumed to "under construction" buildings when height is less than $2.0 \mathrm{~m}$.

\subsubsection{Validation}

The validation of the methodology was performed by comparison between the generated polygons and the reference polygons; the visual aspects, the vertical growth in the overlapping area, and the accuracy per-area level for horizontal detection were analysed.

The horizontal growing was checked first with commission error (False Positive) detected in Lidar survey, but not existent in the reference data. All the polygons were checked with the most recent one source (aerial survey or Google photos), in order to detect classification errors (vegetation or other features detected). These horizontal growth polygons were detached from errors, which is shown in green (Figure 3) and tagged as "new building", when the cadastre was absent. Another exception was made by "cover roofs" (e.g. garages and warehouses) because they are not considered building in the reference cadastre; however, they were detected and mapped as new building when its height was greater than $2.0 \mathrm{~m}$ and its built area was computed.

The polygons smaller than $20 \mathrm{~m}^{2}$ were tagged because of the criteria in the segmentation (minimum 200 points), since a hypothetical and homogeneous distribution should be equivalent.

The True Positive (TP), False Positive (FP) and False Negative (FN) values were calculated to obtain completeness, correctness and quality index, according to the validation methods standardized by the International Society for Photogrammetry and Remote Sensing (Rottensteiner et al., 2014).

The maps in Figure 3 include the False Negative (dotted blue) and False Positive (dotted red) errors computed in a per-area level; Table 4 shows the values for these errors. The vertical growth was computed only for matching areas (True Positive) as the vertical floors difference between results and reference attributes (additional number of floors graded from yellow to red). Negative vertical growth was assumed as demolition (grey).

\begin{tabular}{|l|c|c|c|c|c|c|c|c|}
\hline Name & $\begin{array}{c}\text { Reference } \\
\text { area }\left(\mathrm{m}^{2}\right)\end{array}$ & $\begin{array}{c}\text { Result area } \\
(\text { except horiz. } \\
\text { growth })\end{array}$ & $\begin{array}{c}\text { True } \\
\text { Positive } \\
\left(\mathrm{m}^{2}\right)\end{array}$ & $\begin{array}{c}\text { False } \\
\text { Positive } \\
\left(\mathrm{m}^{2}\right)\end{array}$ & $\begin{array}{c}\text { False } \\
\text { Negative } \\
\left(\mathrm{m}^{2}\right)\end{array}$ & $\begin{array}{c}\text { Completeness } \\
(\%)\end{array}$ & $\begin{array}{c}\text { Correctness } \\
(\%)\end{array}$ & $\begin{array}{c}\text { Quality } \\
(\%)\end{array}$ \\
\hline GUA & 25315.92 & 23255.36 & 21375.31 & 2024.74 & 4166.18 & $83.7 \%$ & $91.3 \%$ & $77.5 \%$ \\
\hline PIO & 17574.71 & 15695.73 & 12921.85 & 1793.87 & 3722.39 & $77.6 \%$ & $87.8 \%$ & $70.1 \%$ \\
\hline MOR & 20588.44 & 16511.56 & 15337.34 & 1267.37 & 5559.04 & $73.4 \%$ & $92.4 \%$ & $69.2 \%$ \\
\hline CAN & 11696.27 & 10283.65 & 8376.94 & 1074.11 & 3474.29 & $70.7 \%$ & $88.6 \%$ & $64.8 \%$ \\
\hline OLA & 16410.41 & 13272.18 & 12296.01 & 801.18 & 4324.75 & $74.0 \%$ & $93.9 \%$ & $70.6 \%$ \\
\hline LUA & 20886.99 & 18634.07 & 17189.30 & 1691.27 & 4225.06 & $80.3 \%$ & $91.0 \%$ & $74.4 \%$ \\
\hline
\end{tabular}

Table 4. Quality assessment per-area level

\subsubsection{Settlement metric}

A premise from $\mathrm{Yu}$ et al. (2010) was adapted here as "the boundary delimited footprint represents the planimetric shape of a building measuring the Building Coverage Ratio (BCR) of the building density in two-dimension (2D) space, and the value of Floor Area Ratio (FAR) is determined not only by the planimetric shape of the building, but also by the vertical distribution of the floors in different height, it depicts the threedimensional (3D) building density".
Instead of the volume, the built area is normally considered by usable area, obtained by each floor of the building. Swimming pools, sport fields, leisure areas, for example, were not considered in this context.

The Floor Area Ratio (FAR) was defined by:

$$
F A R=\frac{\sum_{i=1}^{f} \sum_{j=1}^{b} A i j}{S a}
$$

where: $\quad f=$ number of floors of the building 
$\mathrm{b}=$ number of buildings of the settlement $\mathrm{s}$

$\mathrm{A}=$ building coverage area

$\mathrm{Sa}=$ settlement area

The reference data was considered the initial time to measure the growth (FARREF) until the time of the Lidar survey (FAR ${ }_{\text {NEW }}$, as following:

$$
\text { Growth coefficient }=\text { FAR } \text { NEW }_{-} \text {FAR }_{\text {REF }}
$$

The FARNEW comprises the horizontal built area growth (new buildings and the calculated floors).

\section{RESULTS AND DISCUSSION}

The produced maps (Figure 3) represent the settlements typomorphology in a way that the colours emphasize both vertical and horizontal growth. The errors FP and FN were also represented on the same maps and their visual analysis show a random and homogeneous distribution for the six areas. The numerical analysis of the errors is synthesized in Table 5, with the polygons counting separately according to the sizes below and above $20 \mathrm{~m}^{2}$; however, small buildings with fewer than 200 points have been detected (see the "Min Area" column) due to the heterogeneous distribution in the point cloud. The area covered by building polygons was computed in the $6^{\text {th }}$ column. The minimum and maximum number of floors were presented to measure the verticalization of the areas. Finally, the last column displays the counting for polygons detected as new, i.e. as the horizontal growth. Table 6 summarizes the FAR coefficients from the reference survey to the result data based on the values of the built area (reference in the $4^{\text {th }}$ column and result in the $6^{\text {th }}$ column). The last column presents the coefficients aiming to show the built area growth.

\subsection{Building detection}

The presence of a considerable amount of buildings with less than $20 \mathrm{~m}^{2}$ (13\% to $41 \%$ ) in the reference data contributed to the occurrence of high omission (False Negative). This limitation factor was considered in the results due to the presence of small objects such as water reservoirs or TV antennas on the ceiling; these objects should not be detected as roofs. Each polygon detected is considered as an only building in the results, however, there were buildings with more than one roof at different heights, regarded as just one polygon in the reference file, but subdivided in the result.

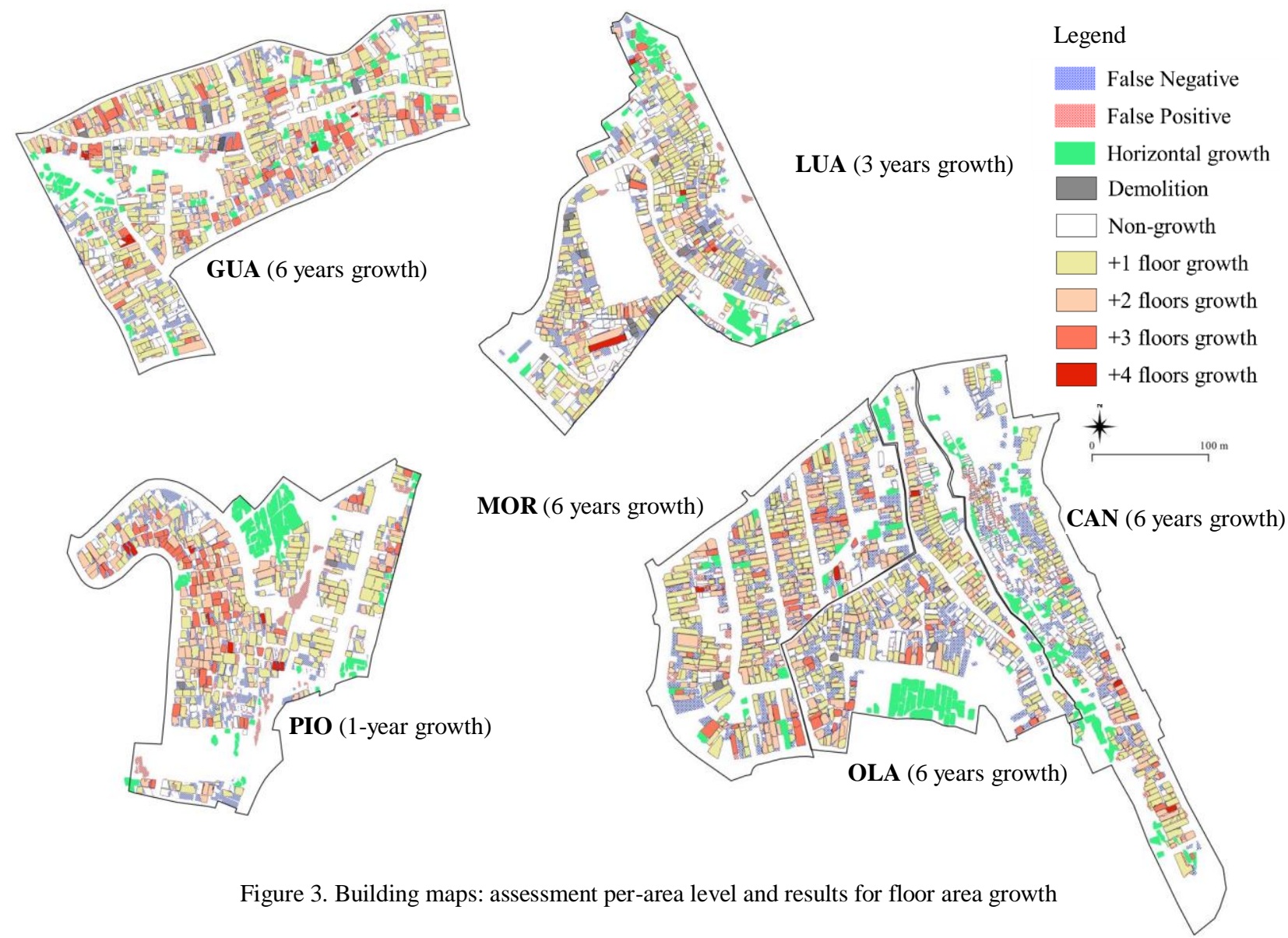

\subsection{Cartographic representation}

We did not give relevance to realistic appearance to the building gables, or even to straight and parallel lines, because our emphasis was to detect the growth of the area built from the reference survey at a Level of Detail 1 (LoD1); we did not consider here the cartographic production with a formal representation, instead of this, useful information about these buildings can be inserted e.g., in 3D framework for a collaborative environment (see Arias de Reyna \& Simoes, 2016 and Yao et al., 2018).

\subsection{Floor height calibration}

The growth coefficient may have been overestimated due to the unique threshold to the floor height assumed for all the buildings; the height of the floor is not homogeneous for different favelas. The lowest floor height is commonly observed in the most precarious typology; wood buildings (which were 
rare) were lower, with less than $3,0 \mathrm{~m}$ and masonry buildings (most common) are greater than 3,0 m. OLA presents similar buildings heights, but the results were different due to the modification of the terrain perceived by the difference between the DTM adopted (2004) and the DTM generated by the recent data (land cuts and fills).

\subsection{A metric for the built area growth}

The highest growth coefficient was for the PIO area, which was $74 \%$ for only one year. The CAN and LUA showed lesser growth, equal to $29 \%$ in six years and $39 \%$ in three years, respectively; however, LUA presented 1.25 for the FAR, despite a preserved free area for a football/soccer field. GUA is the most verticalized, with the highest value to FAR equal to 1.65; its buildings occupy sloped terrains with only one floor on the frontal facades, however, the opposite side of the building had two or more facades and vice-versa.

\subsection{Typo-morphology}

MOR is clearly more developed, showing the typo-morphology similar to the formal areas of the city; it is a typical Irregular parcelling. CAN is the typical typo-morphology of the favelas, with small and low buildings and has the lowest growth coefficient, with a large contribution of horizontal growth (green).

\begin{tabular}{|l|c|c|c|c|c|c|c|c|}
\hline Name & $\begin{array}{c}\text { N. poligs } \\
\text { area } \geq 20 \mathrm{~m}^{2}\end{array}$ & $\begin{array}{c}\text { N. poligs } \\
\text { area }<20 \mathrm{~m}^{2}\end{array}$ & $\begin{array}{c}\text { Min } \\
\text { area } \\
\left(\mathrm{m}^{2}\right)\end{array}$ & $\begin{array}{c}\text { Max } \\
\text { area } \\
\left(\mathrm{m}^{2}\right)\end{array}$ & $\begin{array}{c}\text { Built } \\
\text { coverage } \\
\text { area }\left(\mathrm{m}^{2}\right)\end{array}$ & $\begin{array}{c}\text { N. } \\
\text { floor } \\
\text { min. }\end{array}$ & $\begin{array}{c}\text { N. } \\
\text { floor } \\
\text { max. }\end{array}$ & $\begin{array}{c}\text { New } \\
\text { building }\end{array}$ \\
\hline GUA & 440 & $197(31 \%)$ & 2.64 & 199.26 & 25222.22 & 1 & 7 & 87 \\
\hline PIO & 347 & $220(39 \%)$ & 1.97 & 220.92 & 19269.05 & 1 & 7 & 70 \\
\hline MOR & 277 & $14(5 \%)$ & 11.39 & 321.07 & 17983.47 & 0 & 6 & 20 \\
\hline CAN & 201 & $8(4 \%)$ & 16.1 & 275.20 & 11893.68 & 1 & 5 & 56 \\
\hline OLA & 249 & $12(5 \%)$ & 12.96 & 358.57 & 15602.54 & 1 & 5 & 11 \\
\hline LUA & 363 & $20(5 \%)$ & 4.73 & 467.31 & 20586.41 & 1 & 6 & 33 \\
\hline
\end{tabular}

Table 5. 2017-year survey results

\begin{tabular}{|l|c|c|c|c|c|c|}
\hline Name & $\begin{array}{c}\text { Settlement } \\
\text { area }\left(\mathrm{m}^{2}\right)\end{array}$ & $\begin{array}{c}\text { Reference } \\
\text { vertical built } \\
\text { area }\left(\mathrm{m}^{2}\right)\end{array}$ & $\begin{array}{c}\text { Initial date } \\
\text { reference } \\
\text { FAR }\end{array}$ & $\begin{array}{c}\text { Result } \\
\text { vertical built } \\
\text { area }\left(\mathrm{m}^{2}\right)\end{array}$ & $\begin{array}{c}\text { Survey } \\
\text { date result } \\
\text { FAR }\end{array}$ & $\begin{array}{c}\text { Growth } \\
\text { coeff. }\end{array}$ \\
\hline GUA & 44915.28 & 43785.61 & 0.97 & 74509.46 & 1.65 & $68 \%$ \\
\hline PIO & 41184.06 & 32962.86 & 0.80 & 63259.45 & 1.53 & $74 \%$ \\
\hline MOR & 38611.39 & 37953.27 & 0.98 & 59315.48 & 1.53 & $55 \%$ \\
\hline CAN & 34187.88 & 12872.67 & 0.37 & 22943.92 & 0.67 & $29 \%$ \\
\hline OLA & 33471.34 & 29962.93 & 0.89 & 46760.18 & 1.39 & $50 \%$ \\
\hline LUA & 42507.56 & 36671.74 & 0.86 & 53152.2 & 1.25 & $39 \%$ \\
\hline
\end{tabular}

Table 6. Favela built area growth

\section{CONCLUSIONS}

The results presented here contribute to the decision makers and planners when describing the favela's built area growth quantitatively. In an automated way, the results reached out enough precision to compute the Floor Area Ratio, as a measure for the verticalization, showing the growth trend in the favelas of the Sao Paulo mega city. The feasibility of growing monitoring based on automatic Lidar data processing could be shown, revealing FAR values from $29 \%$ to $74 \%$ for six sample areas at diverse reference dates. The essential geometric quality analysis supports the application investigated with horizontal results from $64.8 \%$ to $77.5 \%$ in the quality assessment. This is an acceptable value, considering that the favela typomorphology is rather complex and similar result have not been produced until now.

As future works, we have two recommendations: (a) Using older photos or maps (if available) can produce a DTM before occupation with no influence of the new buildings. This will be a way to avoid floors definition considering only the terrain surrounding the building, and mainly to avoid the occlusion by high density / agglomerated buildings in established settlements. (b) A refinement of the built area calculation may be considered using the uncertainty of the roof height, resulting in a range value instead of the absolute as presented here. The application of a transition threshold to the number of floors definition based on median height of the roof should significantly increase the quality of the results.

\section{ACKNOWLEDGEMENT}

The experimental work was conducted in a supervised $\mathrm{PhD}$ exchange visiting during six months at Institute of Photogrammetry and Remote Sensing of the Technische Universität Dresden and it was supported by Urbanism Department of the Sao Paulo City Hall.

\section{REFERENCES}

Alexander, C., Smith-Voysey, S., Jarvis, C., Tansey, K. 2009. Integrating building footprints and LiDAR elevation data to classify roof structures and visualise buildings. Computers, Environment and Urban Systems, 33(4):285-292. ISSN 01989715. https://doi.org/10.1016/j.compenvurbsys.2009.01.009.

Arias de Reyna, M., \& Simoes, J. 2016. Empowering citizen science through free and open source GIS. Open Geospatial Data, Software and Standards. http://doi.org/10.1186/s40965$\underline{016-0008-\mathrm{x}}$

Awrangjeb, M. 2015. Effective Generation and Update of a Building Map Database Through Automatic Building Change Detection from LiDAR Point Cloud Data. Remote Sens. 2015, 7, 14119-14150; https://www.mdpi.com/2072-4292/7/10/14119

Balsa-Barreiro, J., Avariento, J. P., Lerma, J.L. 2012. Airborne light detection and ranging (lidar) point density analysis. Scientific Research and Essays, 7(33):3010-3019 
Cao, R., Zhang, Y., Liu, X., Zhao Z. 2017. 3D building roof reconstruction from airborne LiDAR point clouds: a framework based on a spatial database, International Journal of Geographical Information Science, 31:7, 1359-1380. https://doi.org/10.1080/13658816.2017.1301456

Gevaert, C.M., Sliuzas, R., Persello, C., Vosselman, G. 2017. Informal settlement classification using point-cloud and imagebased features from UAV data. ISPRS J. Photogramm. Remote Sens. 125, 225-236.

IBGE - Brazilian Institute for Statistics and Geography. 2010. Censo Demográfico 2010. Rio de Janeiro, IBGE.

Ioannidis, C., C. Psaltis and C. Potsiou. 2009. Towards a strategy for control of suburban informal buildings through automatic change detection. Computers, Environment and Urban Systems 33: 64-74.

Jarzabek-Rychard, M. \& Borkowski, A. 2016. 3D building reconstruction from ALS data using unambiguous decomposition into elementary structures. ISPRS J. Photogrammetry Remote Sensing. 118, pp. 1-12.

Jarzabek-Rychard, M. \& Maas, H-.G. 2017. Geometric Refinement of ALS-Data Derived Building Models Using Monoscopic Aerial Images. Remote Sens. 9(3) pp. 282

Kolbe, T.H. Representing and Exchanging 3D City Models with CityGML. In: Lee, J. \& Zlatanova, S. (Eds.) 3D GeoInformation Sciences, 2009. Springer Berlin Heidelberg. pp.1531

Kuffer, M.; Pfeffer, K.; Sliuzas, R. 2016. Slums from Space15 Years of Slum Mapping Using Remote Sensing. Remote Sens., 8, 455.

Lall, S.V., Wang, H.G., Da Mata, D. Do Urban Land Regulations Influence Slum Formation? Evidence from Brazilian Cities. 2007. "Do Urban Land Regulations Influence Slum Formation? Evidence From Brazilian Cities," Proceedings of the 35th Brazilian Economics Meeting 119, Brazilian Association of Graduate Programs in Economics.

Lu, Z., Im, J., Rhee, J., Hodgson, M. 2014. Building type classification using spatial and landscape attributes derived from LiDAR remote sensing data. Landscape and Urban Planning, 130: 134-148

Maas, H.-G.; Vosselman, G. 1999. Two algorithms for extracting building models from raw laser altimetry data. ISPRS J. Photogrammetry Remote Sensing. 54 (2-3), pp. 153-163.

Mahabir, R., Croitoru, A., Crooks, A. T., Agouris, P., Stefanidis, A. 2018. A Critical Review of High and Very HighResolution Remote Sensing Approaches for Detecting and Mapping Slums: Trends, Challenges and Emerging Opportunities. Urban Sci., 2, 8. https://doi.org/10.3390/urbansci2010008

Martine G. \& McGranahan, G. Brazil's early urban transition: what can it teach urbanizing countries? International Institute for Environment and Development - IIED and United Nations Population Fund - UNFPA. 2010. Available at: http://www.iied.org/pubs/display.php?o=10585IIED . Accessed in: 03.05 .2018

Moreira, A., Santos, M.Y. 2007. Concave hull: A k-nearest neighbours approach for the computation of the region occupied by a set of points. GRAPP 2007, Proceedings of the Second International Conference on Computer Graphics Theory and Applications, Barcelona, Spain, March 8-11, 2007, Volume GM/R
Oude Elberink, A. 2010. Acquisition of 3D topography: Automated $3 D$ road and building reconstruction using airborne laser scanner data and topographic maps. PhD Thesis, ITC, The Netherlands.

Pasternak, S. \& D’Otaviano, C. 2016. Squatter settlements in Brazil and in São Paulo: improvements in the analyzes from the 2010 Census Territorial Reading. Cad. Metrop. [online]. vol.18, n.35, pp.75-100. ISSN 1517-2422. http://dx.doi.org/10.1590/2236-9996.2016-3504

Ribeiro, S.C.L.; Daniel, M.N.; Abiko, A. 2016. ZEIS maps: Comparing areas to be earmarked exclusively for social housing in São Paulo city. Land Use Policy. 58, pp. 445-455. ISSN 0264-8377, https://doi.org/10.1016/j.landusepol.2016.08.010 .

Rottensteiner, F., Sohn, G., Gerke, M., Wegner, J.-D., Breitkopf, U., Jung, J., 2014. Results of the ISPRS benchmark on urban object detection and 3D building reconstruction. ISPRS J. Photogrammetry Remote Sensing 93, pp. 256-271.

Rupnik B., Mongus D., Zalik B. 2015. Point Density Evaluation of Airborne LiDAR Datasets. Journal of Universal Computer Science, 21, 4, 587-603

Sampath, A., \& Shan, J. 2008. Building Roof Segmentation and Reconstruction from Lidar Point Clouds Using Clustering Techniques. The International Archives of the Photogrammetry, Remote Sensing and Spatial Information Sciences. Vol. XXXVII. Part B3a. Beijing.

Saule Jr., N. (Coord). 1999. Direito à cidade: trilhas legais para o direito às cidades sustentáveis. São Paulo: Max Limonad.

Taubenböck, H., Kraff, N. J. 2014. The physical face of slums: a structural comparison of slums in Mumbai, India, based on remotely sensed data. J Hous and the Built Environ 29:15-38. https://doi.org/10.1007/s10901-013-9333-x

Taubenböck, H., Kraff, N.J., Wurm, M. 2018. The morphology of the Arrival City - A global categorization based on literature surveys and remotely sensed data. Applied Geography. 92, pp. $150-167$

Temba, P.; Nero, M.A.; Botelho, L.M.R.; Lopes, M.E.C. 2015. Building Vectorization inside a Favela Utilizing Lidar Spot Elevation. In: Proceedings of the Earth Observing Systems, San Diego, CA, USA

Wang, R. 2013. 3D building modeling using images and LiDAR: a review. International Journal of Image and Data Fusion, 4:4, 273-292, https://doi.org/10.1080/19479832.2013.811124

Wang, R., Peethambaran, J., Chen,. D. 2018. LiDAR Point Clouds to 3-D Urban Models: A Review. IEEE J. of Selected Topics in Applied Earth Obs. and Remote Sensing, 11(2). https://ieeexplore.ieee.org/document/8253517

Yao, Z., Nagel, C., Kunde, F., Hudra, G., Willkomm, P., Donaubauer, A., Kolbe, T. H. 2018. 3DCityDB - a 3D geodatabase solution for the management, analysis, and visualization of semantic 3D city models based on CityGML. Open Geospatial Data, Software and Standards. http://doi.org/10.1186/s40965-018-0046-7

Yu, B., Liu, H., Wu, J., Hu, Y., Zhang, L. 2010. Automated derivation of urban building density information using airborne LiDAR data and object-based method. Landscape and Urban Planning, 98 pp. 210-219. 